\title{
Os grupos tróficos em Coleoptera ${ }^{1}$
}

\section{Renato C. Marinoni ${ }^{2}$}

\begin{abstract}
The trophic groups in Coleoptera. The beetles are a useful group for studies on trophic structure of communities, mainly in forested areas. These kind of studies are based on food habits of species groups. The different terms applied to nomminated these groups (trophic category, ecologic group, trophic group, guild, trophic guild) are discussed. The term trophic group, a natural unity, is proposed to form a group of species with the same food habits, not considering the trophic level. The guild, an artificial unity, is recognized as an important tool to group organisms group that use the same resources as defined by the investigator (HAwKINS \& MA. CMAHON, 1989; SimBerLofF \& DAYAN 1991; WILSON 1999). The known alimentary habits of Coleoptera are classified in five trophic groups - herbivores, algivores, fungivores, detrivores and carnivores. Within each trophic group, subgroups are recognized. The subgroup are in a lower hierarchic level and are defined by morphological (herbivores), taxonomic (fungivores) atributes of the food, by the food origin (detrivores) and by the way that the food is obtained (carnivores). A food resource diagram showing connections among the trophic groups, based on consumer-consumed (predator-prey) relations, is presented.
\end{abstract}

KEY WORDS. Coleoptera, trophic groups, guilds, communities, trophic structure

São vários os trabalhos que buscam interpretar condições ambientais a partir da análise da dominância relativa de agrupamentos tróficos em estruturas de comunidades de diferentes táxons animais, dentre eles os Coleoptera (MORRIS 1980; HUTCHESON 1990; GASTON et al. 1992; MARINONI \& DUTRA 1997; DidHAM et al. 1998; CARLTON \& ROBINSON 1998). Existem diferentes denominações para os agrupamentos de espécies, bem como há dificuldade de se estabelecer, com base nos conhecimentos atuais, a correta identificação do hábito alimentar das espécies e a sua conseqüente inclusão em um agrupamento trófico. Nas análises tem sido utilizado principalmente o conhecimento da biologia de algumas espécies e extrapolada esta informação para as demais espécies de táxons superiores (gênero, tribo, família) enquanto não surgem novos dados biológicos. As denominações sob as quais se estabeleceram os agrupamentos de espécies em estudos ecológicos têm sido as mais diversas, de grupo ecológico a guilda (HAWKINS \& MACMAHON 1989; SIMBERLOFF \& DAYAN 1991; WILSON 1999). Com a visão destas dificuldades foi feita uma revisão dos conceitos que definem estes agrupamentos tróficos: discutindo-se a adequação dos termos utilizados para agrupar espécies com semelhantes hábitos alimentares dentro de estudos ecológicos que incluem besouros ou, mais amplamente, insetos; reconhecendo-se a existência de grupos tróficos onde podem ser reunidos os Coleoptera.

1) Contribuição número 1265 do Departamento de Zoologia, Universidade Federal do Paraná.

2) Departamento de Zoologia, Universidade Federal do Paraná. Caixa Postal 19020, 81531-990 Curitiba, Paraná, Brasil. Bolsista do CNPq. 


\section{Estudos DE COMUNIDADES DE COLEOPTERA}

$\mathrm{Na}$ literatura encontra-se referências à dominância quantitativa e qualitativa dos Coleoptera (cerca de 30\% de todas as espécies animais e presente na maioria dos ambientes terrestres, não sendo encontrados apenas nos mares abertos) em relação a todos os demais grupos taxonômicos constituintes da fauna (PENNY \& ARIAS 1982; LAWRENCE \& BRITTON 1991). Ao lado de caracteres morfológicos básicos, entre os quais a presença de élitros e a posição dos espiráculos abdominais que, abrindo-se em uma câmara de ar formada entre o élitro e o abdômen, permitem a presença de várias espécies em locais extremamente secos, os besouros têm um aparelho bucal do tipo mastigador. Este tipo de aparelho, que permite partir e triturar os alimentos, apresenta ainda modificações adaptativas (predadores, fungívoros, xilófagos e outros), principalmente naqueles com digestão extra-oral, e é reconhecido como um grupo hábil no uso de todos os recursos de energia (alimento) disponiveis na natureza, só não havendo referências à hematofagia (LIMA 1952-56; CROWSON 1981; COSTA et al. 1988; LAWRENCE \& BRITTON 1991).

Estas características, associadas às condições de desenvolvimento ontogenético de muitos grupos que utilizam diferentes ambientes e alimentos nas fases larval e adulta, têm sido referidas como fundamentais para que os Coleoptera sejam considerados como um táxon ordinal representativo (não só da fauna dos insetos como também dos invertebrados) em estudos ecológicos, com destaque para os que tratam de diversidade ambiental através de comunidades. A diversidade de Coleoptera, analisada isoladamente ou como parte de uma fauna de insetos e/ou artrópodos, tem sido relacionada aos diferentes tipos de interações que se estabelecem entre agrupamentos tróficos dentro de uma teia alimentar. A estes estudos juntam-se os que relacionam os níveis de dominância dos agrupamentos tróficos a diferentes áreas naturais, preservadas ou em processo de regeneração nas várias fases de sucessão vegetal (aspectos taxonômicos e/ou estruturais espacial e arquitetônico) (EVANS \& MURDOCH 1968; SOUTHWOOD et al. 1979; MORRIS 1980; BUTT et al. 1980; TANAKA \& TANAKA 1982; MORAN \& SOUTHWOOD 1982; SOUTHWOOD et al. 1982; MOEED \& MEADS 1985; PARMENTER \& MACMAHON 1987; STORK 1987; HUTCHESON 1990; GASTON et al. 1992; SIITONEN 1994; KAILA et al. 1994; MUONA \& RUTANEN 1994; MARINONI \& DUTRA 1997; DIDHAM et al. 1998; CARLTON \& ROBINSON 1998; HUTCHESON \& JONES 1999).

MORRIS (1980), no primeiro estudo com referência exclusiva à fauna de Coleoptera, observou uma variação das espécies com as diferentes fases da sucessão vegetal em uma área de gramíneas, passando de uma forte dominância de espécies fitófagas nos primeiros estágios para a dominância de espécies detritívoras e fungivoras nos estágios mais avançados. BROWN \& HYMAN (1985) acompanharam o desenvolvimento da diversidade de coleópteros fitófagos (Curculionidae e Chrysomelidae) em áreas que se apresentavam em diferentes estágios de sucessão vegetal. HUTCHESON (1990), analisando o produto da captura de coleópteros em diferentes áreas de sucessão vegetal, concluiu que havia uma inversão na dominância das espécies de Coleoptera, de herbívoros para fungívoros-detritívoros, de uma área de vegetação arbustiva para uma floresta de folhas largas. GASTON et al. (1992) compararam a fauna de besouros predadores e não-predadores obtidos através de 
vários métodos de amostragem e captura em vários ambientes, tendo concluído haver uma predominância de predadores nas regiões temperadas em relação às regiões tropicais; e que nas coletas de solo há uma maior proporção de predadores que nas coletas com armadilhas Malaise e nas obtidas com fumigação. MARINONI \& DUTRA (1997) analisando os resultados do levantamento de coleópteros em oito diferentes áreas florestadas observaram a existência de diferentes níveis de dominância de guildas tróficas (fitófagos e não-fitófagos) em áreas com diferentes níveis de preservação vegetal. Recentemente, DiDHAM et al. (1998) analisaram a composição da fauna de besouros coletada em folhiço e constataram a variação na diversidade de espécies e na abundância relativa entre agrupamentos tróficos em diferentes áreas (borda e interior) de fragmentos de floresta. CARLTON \& ROBINSON (1998), também estudando material colhido em folhiço, levantaram dados sobre a diversidade de espécies em uma floresta decídua como base para futuras comparações na mesma área ou com outras áreas atingidas por alterações naturais ou antropogênicas; HUTCHESON \& JONES (1999), utilizando armadilha Malaise, estudaram a diversidade de coleópteros no processo de sucessão dentro de um sistema vegetal homogêneo, representado por vários talhões de uma plantação de Pinus radiata com várias idades ( 5 a 30 anos).

$\mathrm{Da}$ mesma forma que são reconhecidas as qualidades dos Coleoptera para estudos ecológicos, são destacadas as dificuldades de identificação taxonômica ao nível de espécie, e mesmo de gênero, somadas aos poucos dados sobre o comportamento das espécies. As constatações de insuficientes conhecimentos estão registradas, além de outros, em MORRIS (1980) - dificuldade de contar com taxônomos para realizar as identificações; GASTON et al. (1992) - um imperfeito conhecimento da biologia das espécies; MARINONI \& DUTRA (1997) - falta de dados sobre o comportamento alimentar; DIDHAM et al. (1998) - cerca de 90\% das espécies não estão descritas; CARLTON \& ROBINSON (1998) - falta de revisões taxonômicas e informações inadequadas sobre a história natural das espécies.

Em quase todos estes trabalhos, as espécies têm sido identificadas mormente como morfo-espécies, assinaladas para um gênero quando possível, ficando as principais análises circunscritas às relações ao nível de família. É óbvio que a identificação ao nível de espécie seria de extrema valia na interpretação dos resultados que envolvam quaisquer estudos em que se procure estabelecer as relações entre fauna e flora, de sorte a poder, através de padrões, reconhecer condições ambientais (estágios de sucessão vegetal ou de preservação de área). Não só por permitir comparações temporais e espaciais (entre áreas zoogeograficamente semelhantes), como para facilitar o reconhecimento do hábito alimentar de cada uma das espécies com biologia conhecida. No entanto, quando se analisarem faunas de áreas zoogeográficas diferentes, as espécies serão diferentes em sua maioria ou na totalidade. Neste sentido, a identificação taxonômica ao nível de espécie é irrelevante, na medida em que as análises das relações ecológicas entre flora e fauna serão estabelecidas com base no hábito alimentar que, na maioria dos Coleoptera, são semelhantes ao nível taxonômico de família e subfamília, com as exceções quase sempre sendo encontradas ao nível de espécie, e muito raramente de gênero. Desta forma, nos estudos que relacionam agrupamentos tróficos, o esforço de identificação 
fica minimizado bastando, na maioria dos casos, que se saiba o hábito alimentar do táxon mais superior que envolva todas as espécies de mesmo comportamento alimentar. Em Coccinellidae, por exemplo, todas as espécies com hábitos alimentares conhecidos da subfamília Epilachninae são herbívoras; todas as espécies da tribo Psylloborini (Coccinellinae) são fungivoras; todas as demais espécies têm hábito carnívoro (predadoras de afideos, cochonilhas, aleirodídeos) (HODEK 1996).

\section{Denominações dos agrupamentos de espécies que usam o mesmo tipo de alimento}

$\mathrm{Na}$ tabela I estão relacionados alguns dos estudos que trataram das relações entre grupos de espécies de uma dada comunidade que utilizam uma mesma fonte de recurso alimentar. Dentre os vários autores citados, EvANS \& MURDOCH (1968) analisaram relações tróficas em uma comunidade de insetos de campo; HEATWOLE \& LEVINS (1972) trataram da estabilidade da estrutura trófica da comunidade de artrópodos não aquáticos em uma área de mangue; BUTT et al. (1980) relacionaram a dependência da comunidade de artrópodos à sucessão vegetal em áreas de campo devastadas para implantação de linhas de energia elétrica, e DiDHAM et al. (1998) analisaram a estrutura trófica de Coleoptera em fragmentos florestais tropicais. Por estes autores, e pelos demais, foram utilizados os termos categoria trófica, guilda e grupo trófico dentro de um mesmo conceito que foi o de constituir grupos de espécies de uma dada comunidade (seja de Coleoptera em particular, seja de Insecta ou de Arthropoda) que utilizam uma mesma fonte de recurso alimentar, parte de uma teia (herbívoros, detritívoros, etc.), como por eles definidos.

$\mathrm{Na}$ tabela II estão indicadas várias outras pesquisas que também tomaram um grupo de espécies como unidade de estudo, porém sendo principalmente descritivas, não estabelecendo comparações dentro de uma teia alimentar. Trataram de um grupo de espécies que se identificava como possuidor de um tipo semelhante de hábito alimentar associado a um hospedeiro, como Coulson et al. (1986), SIMANDL (1993) e KiSTLER (1995); ou que tinham a mesma característica fisiológica de obtenção do alimento, como HAWKINS (1988); ou que utilizavam o alimento condicionado às características morfológicas e/ou fisiológicas do hospedeiro, como MiLlS (1994) e JOHNSON \& SiEMENS $(1995,1997)$; ou que utilizavam o alimento disponível em um dado extrato do habitat (SIITONEN 1994; MUONA \& RUTANEN 1994), ou ainda de acordo com as condições temporais e espaciais do recurso utilizado (DEOCA \& HALLFTER 1995; FinN et al. 1999). Nestas pesquisas, a denominação utilizada para englobar as espécies foi guilda, principalmente. Foram empregados também os termos grupo ecológico e assembléia.

Os termos categoria e grupo tróficos têm sido naturalmente empregados como decorrência da associação que foi sendo estabelecida com o estudo dos animais nos diferentes níveis da cadeia alimentar.

O termo guilda foi definido pela primeira vez por Root (1967), como sendo "um grupo de espécies que explora a mesma classe de recursos ambientais e de modo semelhante". Referia-se, então, a quatro diferentes grupos de espécies de plantas que são dependentes de outras plantas para viver: lianas, epífitas, saprófitas e parasitas. 
Tabela I. Estudos de estrutura trófica de comunidades envolvendo espécies de Coleoptera.

\begin{tabular}{|c|c|c|c|c|c|c|c|}
\hline Autor & Evans \& Murdoch & Heatwole \& Levins (1972) & Morris (1980) & Butt et al. $(1980)^{A}$ & Moran \& Southwood (1982) & 'Tanaka \& Tanaka (1982) & Brown \& Southwood (1983) \\
\hline Grupo taxonômico & Insecta & Invertebrata (3) & Coleoptera & Arthropoda & Arthropoda & Coleoptera & Insecta Exopterigota \\
\hline \multirow[t]{2}{*}{ Grupo ecológico } & Categoria trófica & Categoria trófica & & Guilda & Categoria trófica & Guilda & Guilda ou Categoria trófica \\
\hline & $\begin{array}{l}\text { Comedor de flor } \\
\text { Comedor de } \\
\text { folha/caule (1) } \\
\text { Detritivoro (2) } \\
\text { Onivoro } \\
\text { Predador de inseto } \\
\text { Predador de outro } \\
\text { animal } \\
\text { Parasita de inseto }\end{array}$ & $\begin{array}{l}\text { Herbivoro } \\
\text { Broca de madeira } \\
\text { Detritivoro } \\
\text { Necrófago } \\
\text { Formiga } \\
\text { Predador } \\
\text { Parasita }\end{array}$ & $\begin{array}{l}\text { Fitófago } \\
\text { Fungivoro } \\
\text { Decompositor }\end{array}$ & $\begin{array}{l}\text { Herbivoro } \\
\text { Năo herbivoro } \\
\text { Mixed-feeder (nāo } \\
\text { definida) }\end{array}$ & $\begin{array}{l}\text { Fitófago (4) } \\
\text { Fauna epifita } \\
\text { Detritivoro } \\
\text { Formiga } \\
\text { Parasitóide } \\
\text { Turista }\end{array}$ & $\begin{array}{l}\text { Comedor de folhagem } \\
\text { Comedor de semente } \\
\text { Broca de madeira } \\
\text { Detritivoro } \\
\text { Predador }\end{array}$ & $\begin{array}{l}\text { Herbivoro (6) } \\
\text { Fungivoro } \\
\text { Detritivoro } \\
\text { Predador }\end{array}$ \\
\hline
\end{tabular}

Tabela I. Continuação.

\begin{tabular}{|c|c|c|c|c|c|c|}
\hline Autor & Parmenter \& Macmahon (1987) & Stork (1987) & Hutcheson (1990) & Gaston et al. (1992) & Marinoni \& Dutra (1997) & Didham et al. (1998) \\
\hline Grupo taxonômico & Arthropoda & Arthropoda & Coleoptera & Coleoptera & Coleoptera & Coleoptera \\
\hline \multirow[t]{2}{*}{ Grupo ecológico } & Grupo trófico & Guilda & Guilda & Grupo trófico & Guilda & Grupo trófico \\
\hline & $\begin{array}{l}\text { Herbivoro } \\
\text { Fungivoro } \\
\text { Onivoro } \\
\text { Comedor de esterco } \\
\text { Necrófago (7) } \\
\text { Predador }\end{array}$ & $\begin{array}{l}\text { Fitófagos (8) } \\
\text { Pastejador em epifita } \\
\text { Detritivoro (9) } \\
\text { Formiga } \\
\text { Predador (10) } \\
\text { Parasitóide } \\
\text { Turista }\end{array}$ & $\begin{array}{l}\text { Herbivoro } \\
\text { Detritivoro (11) } \\
\text { Predador }\end{array}$ & $\begin{array}{l}\text { Não predador } \\
\text { Predador }\end{array}$ & $\begin{array}{l}\text { Fitófago } \\
\text { Não fitófago }\end{array}$ & $\begin{array}{l}\text { Herbivoro } \\
\text { Xilófago } \\
\text { Xilomicetófago } \\
\text { Fungivoro } \\
\text { Saprófago } \\
\text { Predador }\end{array}$ \\
\hline
\end{tabular}

$\left(^{*}\right)$ Quando o autor assinalou apenas "scavenger", sem dar o conceito, o termo foi traduzido como detritivoro; quando assinala "detritivorous" e "scavenger" este termo foi traduzido como necrófago.

(A) Mais os trabalhos de DITSWORTH et al. (1982), BELEY et al. (1982) e JOHNSON et al. (1983); (B) mais o trabalho de SOUTHWOOD et al. (1982).

(1) Inclui os sugadores de suco interno de plantas; (2) cita "scavenger", mas define como se alimentando de matéria morta e em decomposição; (3) inclui insetos, aracnídeos, isópodos; (4) divisão em a) mastigador; b) sugador; (5) divisão em predador a) de inseto; b) de outros animais; (6) divisão em sugador a) de floema, b) de xilema, c) de mesófilo; (7) divisão em: a) sobre vertebrados, b) sobre insetos; (8) divisão em a) mastigador, b) sugador; (9) inclui fungívoro; (10) divisão em predador a) de insetos, b) de outros animais; (11) inclui fungivoro e necrófago. 
T. Tabela II. Estudos de comunidades baseados em hábitos alimentares e em outros atributos, envolvendo espécies de Coleoptera

\begin{tabular}{|c|c|c|c|c|c|c|}
\hline Autor & Brown (1985) & Coulson et al. $(1986)^{A}$ & Hawkins (1988) & Simandl (1993) & Mills (1994) & Siitonen (1994) \\
\hline Grupo taxonômico & Insetos & Coleoptera Scolytinae & Insetos & Coleoptera xilófagos & Insetos endopterigotos & Coleoptera saproxilicos \\
\hline \multirow[t]{6}{*}{ Grupos ecológicos } & Categorias de herbivoros & Guilda & Nichos de herbivoros & Guilda & $\begin{array}{l}\text { Guildas de parasitóides de } \\
\text { insetos endopterigotos }\end{array}$ & $\begin{array}{l}\text { Grupos ecológicos } \\
\text { baseados no substrato }\end{array}$ \\
\hline & $\begin{array}{l}\text { Defolhador } \\
\text { Minador }\end{array}$ & $\begin{array}{l}\text { Besouros da casca do } \\
\text { pinheiro "pine)" }\end{array}$ & $\begin{array}{l}\text { Herbivoro externo } \\
\text { Semi-encoberto }\end{array}$ & $\begin{array}{l}\text { Broca do lenho em } \\
\text { Frangula ulnus }\end{array}$ & $\begin{array}{l}\text { Uma guilda no ovo do } \\
\text { hospedeiro }\end{array}$ & $\begin{array}{l}\text { Generalistas em madeira } \\
\text { em decomposiçăo }\end{array}$ \\
\hline & Galhador & & Minador & & Três na larva & Especialista em abeto morto \\
\hline & Sugador de seiva & & $\begin{array}{l}\text { Galhador } \\
\text { Encoberto }\end{array}$ & & $\begin{array}{l}\text { Quatro na pré-pupa } \\
\text { Duas na pupa }\end{array}$ & $\begin{array}{l}\text { Especialista em bétula } \\
\text { morta }\end{array}$ \\
\hline & & & Rizófagos & & Duas no adulto & $\begin{array}{l}\text { Em fungos de árvores } \\
\text { mortas }\end{array}$ \\
\hline & & & & & & $\begin{array}{l}\text { Em fungos poliporos de } \\
\text { bétula }\end{array}$ \\
\hline
\end{tabular}

Tabela II. Continuação.

\begin{tabular}{|c|c|c|c|c|c|}
\hline Autor & Muona \& Rutanen (1994) & Kistler (1995) & Johnson \& Siemens $(1995,1997)$ & Deoca \& Hallfter & Finn et al. (1999) \\
\hline Grupo taxonômico & Coleoptera saproxilicos & Coleoptera Bruchidae & Coleoptera Bruchidae & Coleoptera Scarabaeinae & Coleoptera Scarabaeidae \\
\hline \multirow[t]{8}{*}{ Grupos ecológicos } & $\begin{array}{l}\text { Grupos ecológicos baseados no } \\
\text { hábito alimentar e substrato }\end{array}$ & Guilda & Guilda & Guilda & Assembléia "assemblage" \\
\hline & $\begin{array}{l}\text { Predadores ( } 1 \text { ) } \\
\text { Não predadores no solo }\end{array}$ & \multirow[t]{7}{*}{ Semente de "mesquite" } & $\begin{array}{l}\text { Oviposição em vagem madura } \\
\text { Em semente madura }\end{array}$ & \multirow[t]{7}{*}{ Coprófago "burrowing beetles" } & \multirow[t]{7}{*}{$\begin{array}{l}\text { Coprófago "besouros do } \\
\text { esterco" }\end{array}$} \\
\hline & $\begin{array}{l}\text { Atraidas por árvores mortas ou } \\
\text { danificadas }\end{array}$ & & \multirow[t]{6}{*}{ Em semente madura exposta } & & \\
\hline & Espécies associadas à Rodentia & & & & \\
\hline & Em recursos temporarios & & & & \\
\hline & Em madeira atacada por fungo & & & & \\
\hline & Enterradas no solo & & & & \\
\hline & Herbivoros & & & & \\
\hline
\end{tabular}

(A) Mais os seguintes autores: LOVELADY et al. (1991); FLAMM et al. (1993).

(1) divisão em predadores: a) no solo; b) sob a casca de árvore; c) na vegetação. 
A partir daí o termo foi utilizado de diferentes maneiras por vários pesquisadores, conforme bem descrito nos estudos revisivos feitos por HAWKINS \& MACMAHON (1989) e SiMBERLOFF \& DAYAN (1991). Os primeiros concluíram que, embora o conteúdo empírico de guilda tenha aumentado, o conceito é uma construção útil mas artificial da mente de ecólogos e que guilda ainda arrola todos os organismos que usam os mesmos recursos como venha a ser definido pelo pesquisador. SIMBERLOFF \& DAYAN (1991) concluíram que o problema no uso do termo estaria nas várias conotações que o termo guilda adquiriu e que o estreito significado original da palavra dificilmente poderia ser vantajosamente recuperado para uso científico. Referiram-se, então, a duas condições para que tal ocorresse: 1) uma clara indicação de todos os critérios e considerações que levaram a designar uma determinada guilda, com o papel do forrageamento sendo enfatizado devido à sua importância potencial na efetiva diferença no uso dos recursos; 2) a biota simpátrica devendo sempre ser listada e, mais, dada uma explanação das razões pelas quais foram excluídas de uma determinada guilda.

Apesar das críticas referidas acima, esses autores não deixaram de reconhecer a importância do uso de agrupamentos de espécies para relacionar componentes da comunidade que têm hábitos semelhantes independente de suas relações taxonômicas. O emprego de guildas teria as seguintes vantagens, sugeridas por RoOT (1967): 1) concentraria a atenção em todas as espécies simpátricas partilhando ou competindo pelos mesmos recursos, independente de suas relações taxonômicas; 2) o partilhar ou competir por um recurso não implica em ser ocupante de um mesmo nicho; 3 ) útil para estudos comparados de comunidades, já que capacita os pesquisadores a concentrarem estudos em grupos específicos com relações funcionais específicas, quase impossível de ser realizado pela dificuldade de envolver todas as espécies de um ecossistema.

A definição de Root não especifica o tipo de recurso disponível no ambiente a ser utilizado na criação de uma guilda. Mas, ao longo do tempo, a fonte de recursos compartilhada que baseou a constituição de guildas foi o alimento, principalmente. Mas também têm sido usadas guildas que se definem pelo compartilhamento de habitat; pelo tipo de nidificação; pela semelhança de comportamento reprodutivo, e outros, como destacam HAWKINS \& MACMAHON (1989) e SIMBERLOFF \& DAYAN (1991).

SIMBERLOFF \& DAYAN (1991) escreveram que a utilização do termo guilda trófica por BURNS (1989) seria correspondente ao conceito tradicional de nível trófico, pois teria sido definido como sendo um "agrupamento de espécies com uma fonte de recursos tróficos semelhante". Apesar de ter omitido a expressão "in a similar way" em várias citações do conceito de Root, BURNS (1989) estabeleceu uma distinção entre os conceitos baseando-se na quantificação do fluxo de energia (nível trófico) ou não (guilda trófica); sendo o conceito "trophic level... as the sum, over all species populations or components in the ecosystem, of the portions of their energy contents that had been previously assimilated an equal number of times" possível de ser operacionalizado através de um sistema; e guilda trófica tendo a mesma definição de Root sem a expressão "de maneira semelhante".

Mais recentemente, WILSON (1999), como uma decorrência da criação destes vários agrupamentos ecológicos de espécies, reconheceu a todos como guildas, quando escreveu: "they envisage groups of species defined not (primarily) by their 
taxonomy but by their similar ecology", e mais "guild would be: a group of species that are similar in some way that is ecologically relevant, or might be". Propôs uma classificação em guildas Alfa e Beta. As guildas Alfa incluindo todas as que se baseiam no tipo do recurso usado, dentro da comunidade; são as "guildas rootianas" (= rootian guilds). As guildas Beta incluem todas as que se baseiam em uma reunião de espécies de acordo com as condições ambientais, ou melhor, que têm necessidades semelhantes de habitat. Dentro das guildas Alfa existem subdivisões considerando a) a objetividade ou subjetividade dos caracteres definidores, e b) o comportamento das espécies. Dentro das guildas Beta, a subdivisão principal está apoiada nas a) observações da distribuição espacial ou temporal das espécies e b) na mensuração de caracteres que podem ser descritivos ou produto de resposta a fatores ambientais.

Outros termos que surgiram na literatura, ligados a estudos do uso do alimento em comunidades, foram grupo funcional, criado por CUMMINS (1974), e grupo exclusivo dominante (dominant clique) de YoDZIS (1982). Grupo funcional tem sido largamente usado para estudos de invertebrados aquáticos. Mas, diferentemente dos conceitos anteriores que se baseiam na origem do alimento, os grupos funcionais (macro e microconsumidores) foram formados com base nas características físicas do alimento (tamanho das partículas), tendo em vista que o grande aporte de energia em ecossistemas lóticos é fornecido por detritos (folhas, frutos, sementes, etc.) provenientes de ecossistemas vizinhos. Grupo exclusivo dominante, cunhado por YoDzIS (1982), é um conjunto de espécies que compartilham algum recurso alimentar. Aplicou este termo para diferir de guildas que poderiam ser reconhecidas como níveis tróficos de uma cadeia alimentar. O mesmo Yodzis (1993) refere-se aos grupos exclusivos dominantes como sendo guildas tróficas, desde que o conceito de guilda de Rоот (1967) seja observado dentro do contexto de uma teia alimentar.

\section{Niveis tróficos versus grupos tróficos}

Em várias das referências à literatura feitas até aqui, tratou-se de estudos que envolvem comunidades e teias alimentares. $\mathrm{O}$ conceito de comunidade sendo entendido como o conjunto de organismos que vivem em alguma área; e o de teia alimentar como sendo a representação de um conjunto de espécies que vivem juntas com a especificação de quais espécies se alimentam de quais outras espécies. Dentro das convenções da teoria de teias alimentares, uma espécie predadora é aquela que consome alguma outra espécie e uma espécie presa é aquela que é consumida por alguma outra espécie. Com esta visão da característica funcional das espécies numa teia alimentar, COHEN (1978) reconheceu a existência de teias de recursos alimentares, partindo de um conjunto de presas, incluindo todos os seus predadores, e todos os predadores dos predadores, e assim por diante. O conjunto de espécies presas sendo constituído pelas espécies produtoras da cadeia alimentar (vegetais sintetizadores de pigmentos capazes de reter energia) e o conjunto de espécies predadoras reunindo todos os consumidores (primários, secundários e superiores). Como bem demonstrado por YoDzIs (1993), o conceito de teia alimentar é muito diferente de uma cadeia alimentar. Nesta as espécies são organizadas em níveis tróficos, onde os produtores ocupam o primeiro nível; os herbívoros que se alimentam dos produtores pertencem ao segundo nível; os consumidores secundários que conso- 
mem os herbívoros constituem o terceiro nível; os consumidores terciários consomem os secundários (quarto nível), e assim por diante. Neste conceito, o princípio ordenador é a passagem do fluxo de energia através dos diferentes elos da cadeia. Os níveis tróficos de uma cadeia alimentar podem ser coerentes com os agrupamentos de uma teia alimentar, mas não necessariamente semelhantes. Os agrupamentos de espécies são coerentes com os níveis tróficos apenas quando retratam os elementos basais, em que o primeiro nível trófico da cadeia corresponde às espécies presas (produtoras) que não são predadoras de nenhuma espécie e ao segundo nível trófico em que as espécies predadoras (herbívoros, algívoros) apenas consomem presas produtoras. Mas, quando por exemplo se analisam os carnivoros ou detritivoros, a correta identificação do nível trófico é muito difícil, porque um carnívoro pode ser consumidor de um outro carnívoro e porque um detritívoro pode ser o consumidor dos restos de um outro detritívoro ou carnívoro. Nestes casos fica duvidoso o posicionamento das espécies no terceiro, ou quarto, ou ainda níveis tróficos superiores. Seguindo os conceitos acima, o termo grupo trófico é adiante empregado para reunir em uma mesma classe todas as espécies que se utilizam de uma mesma fonte de recurso alimentar, independente do nível trófico e do ecossistema a que pertençam. O termo já foi anteriormente utilizado por outros autores, mas com conceito semelhante ao de guilda, ao reunirem espécies com hábitos alimentares e modo de captura semelhantes, em estudos de comunidades (PARMENTER \& MACMAHON 1987; DiDHAM et al. 1998).

\section{GRupos ECOLÓgICOS ENVOLVENDO ESPÉCIES DE COLEOPTERA}

\section{Agrupamentos baseados no alimento e em outros diferentes atributos}

$\mathrm{Na}$ tabela II estão relacionados alguns dos trabalhos que estabeleceram relações entre a fauna de Coleoptera e o ambiente, utilizando outros atributos para agrupar espécies além do tipo de alimento. MiLls (1994) analisou a estrutura de comunidades de parasitóides reunidos em guildas definidas pelas fases do ciclo de vida do hospedeiro; como fizeram JoHNSON \& SIEMENS $(1995 ; 1997)$ agrupando bruquídeos em diferentes fases do amadurecimento de vagens e sementes de leguminosas. Coulson et al. (1986), Lovelady et al. (1991), Flamm et al. (1993), SIMANDL (1993) e KISTLER (1995) utilizaram uma parte do vegetal como base para agrupar espécies que a utilizavam como alimento; as diferenças entre estes agrupamentos foi que SIMANDL (1993) reuniu espécies xilófagas de várias famílias, KISTLER (1995) as espécies espermófagas de apenas uma família; enquanto que, nos três primeiros trabalhos, as espécies de Scolytidae (besouros da casca) foram agrupadas em guildas definidas pelo estado de saúde da planta, depois de atingidas por relâmpagos. BROWN (1985), para estudos de colonização nos primeiros estágios de sucessão vegetal, distribuiu as espécies herbívoras em categorias de colonização todas relacionadas à maneira como o recurso contido na folha era ingerido (mastigadores, sugadores); HAWKINS (1988), também estudando apenas herbívoros, formou diversos grupos, não apenas no modo com que as espécies obtinham o alimento, mas no espaço físico e em partes da planta que consumiam. DEOCA \& HALFFTER (1995) e FINN et al. (1999) relacionaram a diversidade de espécies de Scarabaeidae, reunindo-as em guildas baseadas nas variações do tempo e no espaço com que se 
alimentam no esterco. SiITONEN (1994) e MuONA \& RUTANEN (1994) pesquisaram a reocupação de um ambiente florestal por besouros saproxílicos após uma queimada, e criaram vários grupos ecológicos apoiados no tipo de substrato e no hábito alimentar.

\section{Agrupamentos baseados apenas no tipo de alimento}

Na maioria dos trabalhos foram constituídos agrupamentos que se assemelham ao conceito de guilda trófica de BURNS (1989) - um grupo de espécies com recursos tróficos semelhantes; que apesar de ser diferente do grupo funcional de CUMMINS (1974), que enfatiza o tamanho e não a origem das partículas alimentares teve, como este, o objetivo de propiciar condições para verificar a hipótese de que a dominância relativa de agrupamentos tróficos muda com diferenças na viabilidade de fontes de energia.

Tanto EVANS \& MURDOCH (1968), como os demais outros autores, relacionados na tabela I, que utilizaram diferentes termos, como categoria trófica, guilda, grupo trófico, o fizeram para indicar a reunião de um grupo de espécies que consumiam um mesmo tipo de recurso alimentar, não caracterizados como um nível trófico de uma cadeia alimentar. Os diferentes agrupamentos de espécies instituídos foram uma decorrência do objetivo de pesquisa como, por exemplo, a ênfase em distinguir dentre os herbívoros, os comedores de folhas e os comedores de lenho, ou ainda, comparar o grupo dos herbívoros ao dos não herbívoros.

Nem todos os trabalhos apresentaram uma clara conceituação dos agrupamentos de espécies, tendo havido alguns onde nem mesmo são relacionadas as espécies ou táxons superiores que são incluídos em cada um deles.

Dentre os agrupamentos, os conceitos de predadores e de parasitas talvez sejam os que menores dúvidas suscitam, porém o dos herbívoros e detritívoros foram utilizados de várias maneiras. O conceito de herbívoro tem duas vertentes. Uma é considerar como herbívoro todo organismo que se alimenta de um organismo produtor (planta, alga), sendo o primeiro a capturar a energia apreendida pelo vegetal. Outra é assumir como herbívoro todo organismo que utiliza um vegetal vivo como alimento (MORAN \& SOUTHWOOD 1982; HUTCHESON 1990). Todas as duas conceituações têm dificuldades para que se interprete e identifique corretamente a situação em que o alimento se encontra quando ingerido pelo consumidor. No conceito que utiliza plantas vivas, há partes da planta que são facilmente identificadas como tal e que se transformam rapidamente quando mortas: principalmente a maioria das folhas, flores e frutos. Outras partes, como tronco e semente não permitem esta caracterização facilmente. Há troncos de árvores quebradas, por exemplo, que separados da parte radicular, rebrotam em contato com o solo. Por outro lado, as sementes, considerando-se que a única parte que mantém o potencial de desenvolvimento vital é o embrião (parte ínfima do conteúdo alimentar a ser ingerido), não podem ser consideradas como partes de uma planta viva. A definição de herbivoro apoiada no conceito de consumidor primário tem melhores condições de aplicação. Dentre os organismos que podem ser incluídos no conceito, a dificuldade de identificação está naqueles que consomem o lenho, em que este pode estar ou não alterado pela ação de fungos e bactérias ou outros microorganismos decom-

Revta bras. Zool. 18 (1): 205 - 224, 2001 
positores. Este substrato, nas suas várias fases de transição (vivo a decomposto) é utilizado pela quase totalidade de espécies de Cerambycidae, Buprestidae, e de várias subfamílias de Curculionidae. Diante desta dificuldade, HEATwOLE \& LEVINS (1972) criaram o grupo dos herbívoros e o das brocas de madeira; e TANAKA \& TANAKA (1982) os grupos dos comedores de folhagem, dos comedores de semente e das brocas de madeira.

O conceito de detritívoro parece claro quando não inclui a condição de que o alimento seja organismo morto e se restringe a indicar como alimento o organismo em decomposição, de origem vegetal ou animal. Os predadores também comem organismos mortos, mas não são considerados detritívoros, considerando-se o fato das estruturas ingeridas não terem sofrido a ação de decompositores (bactérias, fungos, etc.). O mesmo sentido deve ser dado ao uso de um vegetal como alimento, em que a ação do detritívoro se caracteriza pela ingestão de partículas já decompostas.

O conceito de fungivoro ligado à condição do alimento ser um fungo é claro. A dificuldade está, igualmente como a dos detritívoros, em identificar qual o alimento que foi ingerido, já que a maioria dos fungos desenvolvem-se em matéria em decomposição, e muitas vezes o coleóptero ingere ambos os recursos. É pequeno o número de estudos sobre o conteúdo intestinal de coleópteros visando reconhecer o alimento ingerido, sendo alguns deles: HENGEVELD (1980); HollowAY (1982); STRIBLING \& SEYMOUR (1988); PELlMyr (1985); Hering (1998). Resta a observação do ato de ingerir o alimento pelo besouro que é, sem dúvida, muito difícil pelo tamanho diminuto da maioria das espécies detritívoras e fungívoras, principalmente das que vivem no folhiço. Apesar de não ter sido exposta claramente, fica subentendido que foi esta falta de conhecimento sobre hábito alimentar que levou vários autores a não fazerem distinção de grupos para fungívoros e detritívoros, reunindo-os neste último (EVANS \& MURDOCH 1968; HEATWOLE \& LEVINS 1972; MORAN \& SOUTHWOOD 1982; TANAKA \& TANAKA 1982; STORK 1987; HUTCHESON 1990). Ainda como produto da dificuldade de conceituação e da falta de dados sobre hábitos alimentares foi que HEATWOLE \& LEVINS (1972) estabeleceram "formiga" como uma categoria trófica em separado, devido ao hábito onívoro do táxon. O sentido desses autores incluía outros grupos taxonômicos, enquanto em MORAN \& SOUTHWOOD (1982); SOUTHWOOD et al. (1982) e STORK (1987), a categoria incluiu apenas formigas.

Em alguns trabalhos, numa simplificação das comparações, foram estabelecidos apenas dois ou três agrupamentos de espécies, alguns deles contrapondo herbívoros a não-herbívoros (MORRIS 1980; BUTT et al. 1980; DITSWORTH et al. 1982; BELEY et al. 1982; JOHNSON et al. 1983; HUTCHESON 1990; GASTON et al. 1992; MARINONI \& DUTRA 1997).

\section{OS GRUPOS TRÓFICOS EM COLEOPTERA}

A ocupação de um nicho por uma espécie está associada às suas necessidades alimentares e reprodutivas, implicando na busca de espaços que além de suprir esses quesitos lhe propicie proteção. Nos coleópteros este espaço é extremamente diversificado atingindo praticamente todos os ambientes terrestres, grande parte dos 
límnicos e a zona intertidal marinha. Para algumas espécies o nicho é muito restrito em espaço e em fonte de alimento, como o de algumas espécies que vivem em grãos armazenados ou em artefatos produzidos pelo homem com material de origem animal ou vegetal. Há espécies que estão no outro extremo, em que o nicho é muito amplo, já que larvas e adultos têm espaços físicos e hábitos alimentares diferentes. Este comportamento pode ser observado em herbívoros, como Cerambycidae, em que a larva é xilófaga, vivendo inteiramente dentro do lenho, e os adultos, quando se alimentam, são antófagos / polinífagos ou ainda fleófagos; e entre predadores, como Hydrophilidae, Dytiscidae, em que as larvas são predadoras aquáticas e os adultos são terrestres, podendo ser detritívoros ou fungívoros. Esta amplitude de nicho torna complexa uma classificação de espécies de Coleoptera que, sendo a mais generalista possível, as ordene de acordo com os seus hábitos alimentares.

Parece ser adequado utilizar, por princípio, o hábito alimentar das larvas para a inclusão de uma espécie em um dado grupo trófico. A larva é a forma vegetativa onde se observa a ingestão do maior volume de alimento, necessário para o crescimento e formação de todos os órgãos do adulto, inclusive dos reprodutivos. Entre os adultos, ao contrário, a alimentação é basicamente para a manutenção das atividades metabólicas para a realização da cópula e oviposição. Há algumas famílias em que os adultos não comem e em outras a alimentação é restrita e de pouco significado biológico (CROWSON 1981).

\section{Classificação dos grupos tróficos}

Os diferentes hábitos alimentares foram classificados em grupos tróficos (tabela III). Tratando-se de uma classificação e não de uma análise das relações entre as espécies de uma comunidade de besouros é julgado conveniente o uso, neste contexto, do termo grupo trófico para reunir espécies que utilizam um mesmo tipo de recurso alimentar. Apesar da generalização que o termo guilda sofreu (WILSON 1999), e sem pretender aplicar o conceito restritivo (RоOT 1967), preserva-se o seu uso para pesquisas em que, ao ser empregado, conste uma definição de sua abrangência, incluindo simplesmente grupos tróficos ou que incorpore mais atributos como, por exemplo, a forma de obtenção (coletas manuais, armadilhas); ou o elemento temporal e espacial do recurso usado. Desta forma, uma guilda somente poderá ser identificada de acordo com a classificação de WILSON (1999) dentro de uma análise onde se a conceitue claramente (SIMBERLOFF \& DAYAN 1991). O grupo trófico constituindo-se em uma unidade natural, definida pelo hábito alimentar do animal. A guilda sendo uma unidade artificial, definida por objetivos de uma pesquisa (HAWKINS \& MACMAHON 1989). A guilda serve aos propósitos de permitir comparações entre componentes de ecossistemas, quando o pesquisador a compõem reunindo elementos biológicos passíveis de serem descritos como produto de uma clara metodologia de levantamento de dados. A guilda será tanto mais útil quanto maiores forem as possibilidades de repetição do experimento por todos os seus elementos definidores.

São reconhecidos cinco grupos tróficos em que os Coleoptera podem ser arrolados. Os herbívoros e algívoros como consumidores primários; os fungívoros, detritívoros e carnívoros como consumidores secundários ou de nível superior. 
Como ocorre em diferentes estudos ecológicos são observadas situações em que o hábito alimentar da espécie ou é intermediário entre dois conceitos ou pode ser incluído em dois conceitos diferentes, ficando a critério do pesquisador a identificação do hábito e conseqüente inclusão em um agrupamento trófico.

Tabela III. Proposta de organização de grupos e subgrupos tróficos em Coleoptera. Os conceitos dos grupos estão descritos no texto. Para uniformização, todos os nomes de grupos são de origem latina e os de subgrupos são de origem grega, exceto os do grupo dos carnivoros, que foram mantidos pela tradição do uso. Os nomes dos grupos têm como sufixo voros, do latim vorare, significa comer, devorar. Os nomes de subgrupos têm o sufixo fago, do grego phagein, que também significa comer. São indicados apenas alguns dos vários possiveis nomes de subgrupos.

\begin{tabular}{|c|c|c|}
\hline Grupo trófico & Subgrupo trófico & Substrato alimentar \\
\hline \multirow[t]{10}{*}{ Herbivoro } & Filófago & Folha \\
\hline & Xilófago & Lenho \\
\hline & Caulifago & Caule \\
\hline & Fleófago & Floema \\
\hline & Antófago & Flor \\
\hline & Nectarifago & Néctar \\
\hline & Polinifago & Pólen \\
\hline & Carpófago & Fruto \\
\hline & Espermófago & Semente \\
\hline & Rizófago & Raiz \\
\hline \multicolumn{3}{|l|}{ Algivoro } \\
\hline \multirow[t]{4}{*}{ Fungivoro } & Mixomicófago & Mixomicetos \\
\hline & Ascomicofago & Ascomicetos \\
\hline & Basidiomicófago & Basidiomicetos \\
\hline & Deuteromicófago & Deuteromicetos \\
\hline \multirow[t]{3}{*}{ Detritivoro } & Necrofago & Animais em decomposição, cadáveres \\
\hline & Coprófago & Excremento \\
\hline & Fitosaprofago & Restos vegetais \\
\hline \multirow[t]{3}{*}{ Carnivoro } & Predador & $\begin{array}{l}\text { Mata um animal para comer, geralmente duas ou mais presas em sua vida } \\
\text { (TORRE-BUENO 1978) }\end{array}$ \\
\hline & Parasita & $\begin{array}{l}\text { Organismo que vive na superficie - ectoparasita, ou no interior -endoparasita, } \\
\text { de outro animal do qual ele obtém alimento, abrigo ou outras vantagens) } \\
\text { (TORRE-BUENO 1978) }\end{array}$ \\
\hline & Parasitóide & $\begin{array}{l}\text { Insetos cujas larvas desenvolvem-se alimentando-se sobre ou dentro de } \\
\text { artrópodos hospedeiros (MILLS 1994) ou, inseto parasita interno ou externo } \\
\text { que mata lentamente o seu hospedeiro, e este evento ocorre próximo ao fim } \\
\text { do desenvolvimento larval do parasita, segundo TORRE-BUENO (1978) }\end{array}$ \\
\hline
\end{tabular}

Os consumidores primários, herbívoros e algívoros, são os organismos que utilizam como alimento uma parte ou o todo de um organismo produtor, sem que tenha havido transferência (da energia) pela ação de outro organismo decompositor e que também não tenha sido parte do processo de digestão de outro animal.

Os herbivoros são os comedores de plantas ou partes das plantas, como folha, casca, caule, tronco, raiz, flor, fruto, semente. Em todas as situações em que se observa a ingestão de planta morta, ou parte, há a dificuldade de caracterizar a fase de transição que decorre entre a morte da planta (ou de parte) e a ação de agentes decompositores, como bactérias e fungos. O coleóptero que utilizar estas partes anteriormente à ação desses organismos deve ser reconhecido como consumidor 
primário. Exemplo claro desta situação são os Cerambycidae. Há alguns grupos taxonômicos que são complicados para a inclusão em um grupo trófico, como os Scolytidae que apresentam diferentes hábitos alimentares; algumas espécies são xilófagas e fungívoras (xilomicetófagas) durante diferentes fases do ciclo de vida; outras fleófagas, espermófagas, mielófagas ou simplesmente xilófagas (FLECHTMANN et al. 1995).

O outro grupo de consumidores primários é o das espécies que ingerem algas, os algivoros. Este hábito alimentar tem um significado maior em estudos de comunidades de invertebrados aquáticos. As algas foram reconhecidas por CuMMINS (1974) como um importante componente, dentre os organismos produtores da teia alimentar, ao lado das plantas vasculares. Dentre os besouros não há dados sobre o significado das espécies algívoras no fluxo de energia. Há espécies de mais de dez famílias que têm este hábito alimentar, principalmente na fase larval. Algumas delas pouco expressivas quanto à diversidade ou à biomassa, como as de Myxophaga (Microsporidae, Torridincolidae, Hydroscaphidae); outras muito abundantes, como as de Limnichidae (em áreas do Pantanal Mato-grossense, V.J.S.Toledo comunicação pessoal).

Os consumidores secundários e de nível superior constituem três grupos tróficos: os dos fungivoros, dos detritivoros e dos carnívoros.

Os fungivoros incluem todos os comedores de qualquer tipo e parte de fungo: micélio, esporos ou partes selecionadas dos corpos frutíferos de basidiomicetos; e há espécies que estão obrigatoriamente ligadas aos cogumelos, onde procriam e se alimentam, tendo desenvolvido estruturas bucais especializadas como as da subfamília Oxyporinae e do gênero Gyrophaena (Staphylinidae) e as dos Ciidae, associados aos políporos (LAWRENCE 1973; WHITE 1977; MURRIN 1996).

Os detritivoros são os que comem partículas (resíduos, detritos, incluindo líquidos) produto da decomposição de células e tecidos animais ou vegetais. Os grupos dos fungívoros e detritívoros são os que apresentam as maiores dificuldades para o reconhecimento correto das espécies que os constituem. As espécies mais facilmente reconhecidas são as que comem macrofungos, vivendo dentro do hospedeiro, e as que comem micélio e esporos de fungos que se desenvolvem em substratos que estão nos primeiros estágios de decomposição; no entanto, aquelas que comem fungo onde a decomposição está muito mais acentuada e há a mistura dos fungos aos produtos de decomposição (hemiceluloses, açúcares, e humores tissulares e celulares), podem ser confundidas com as espécies detritívoras. Entre os detritívoros há uma variada gama de alimentos de origem vegetal ou animal. Os coprófagos e necrófagos são dois exemplos de organismos que utilizam alimentos de origem animal. Agrupamentos de organismos que comem detritos de origem vegetal, como por exemplo, fitosaprófagos (TORRE-BUENO 1978), têm sido pouco utilizados.

No grupo dos carnívoros são incluídos todos os organismos que se alimentam de tecidos, células ou líquido interno de animal vivo, como os parasitas e parasitóides, ou recém morto pela ação do próprio ingestor do alimento, como os predadores. Apesar da teoria de teia alimentar indicar o nome de espécie predadora para toda aquela que consome uma outra espécie presa, o termo predador foi utilizado neste texto para indicar um agrupamento de espécies carnívoras, com um modo de ação peculiar que é o de matar a espécie animal presa para a consumir. O alimento 
utilizado por predadores, parasitas e parasitóides é o mesmo, ou seja, provém de outro animal. O princípio que norteia a reunião acima é o mesmo que é utilizado na inclusão de diferentes hábitos alimentares dentro dos herbívoros. Os herbívoros como os xilófagos, ingerem planta viva ou recém morta não alterada pela ação de outros decompositores; a ação dos predadores de ingerirem parte ou o todo de animal recém morto situa-se no mesmo nível dos xilófagos.

\section{Os subgrupos tróficos}

Dentro dos grupos tróficos podem ser reconhecidos subgrupos (Tab. III). A formação destes subgrupos tróficos está apoiada em diferentes atributos de cada grupo trófico. Todos os subgrupos são hierarquicamente inferiores aos grupos tróficos por atributos morfológicos, ou taxonômicos, ou fisiológicos. Os subgrupos dos herbívoros são definidos pela ingestão de partes de um todo como, por exemplo, o dos filófagos que reúne as espécies que consomem folha; rizófagos, as espécies que consomem raiz; espermófagos, as espécies que consomem sementes. Os fungívoros podem ter subgrupos definidos pelo grupo taxonômico de fungo que consomem, como os ascomicetófagos, basidiomicetófagos, etc.. Os subgrupos de detritívoros podem ser reconhecidos pela origem da matéria orgânica que ingerem, como coprófagos (fezes), necrófagos (carniça, restos animais), etc. Os subgrupos dos carnívoros são definidos pelo modo como agem para obter $\mathrm{o}$ alimento: os predadores matando a presa; os parasitas consumindo partes, normalmente líquidos internos, das presas, sem as levar à morte; os parasitóides normalmente ingerindo tecidos internos das presas, levando-as à morte.

Se, por um lado, os grupos tróficos propostos podem incluir todos os hábitos alimentares conhecidos, os subgrupos não abrangem todas as possibilidades de reunião de espécies, havendo condições para que outros sejam estabelecidos.

\section{Uma rede de recursos alimentares com base em espécies de Coleoptera}

É utilizado o termo rede, para evitar o uso de teia que tem sido empregado em diagramas que ilustram as relações tróficas dentro de uma comunidade. A rede de recursos alimentares com base em espécies de Coleoptera (Fig. 1) representa os conhecimentos obtidos do levantamento dos hábitos alimentares de Coleoptera realizados por MARINONI et al. (no prelo). O diagrama apresentado não é, obviamente, representativo das relações tróficas que se desdobram em uma localidade específica, mas de todas as possibilidades de interações tróficas que, em tese, possam existir entre as espécies de Coleoptera e o ambiente. Os conceitos embutidos na construção do diagrama são os mesmos encontrados em COHEN (1978) e YoDZIS (1993) quando trataram de teias alimentares. A orientação dada pelas setas que estabelecem ligações entre os grupos não é a do fluxo de energia, mas a de consumo de alimento. O sentido da seta indica a ação de ingestão, do consumidor para o consumido: o carnívoro que consome o detritívoro, que consome o resto de uma planta, ou de um outro inseto, ou de um outro animal, ou de um vegetal; ou ainda o carnívoro que consome outro carnívoro, que consome um herbívoro, que consome uma planta. A seta em linha sólida indica a ação de ingestão de um consumidor primário e a seta tracejada a ação de um consumidor secundário ou de nível superior. As diferentes formas geométricas representam as diferentes fontes de recursos 


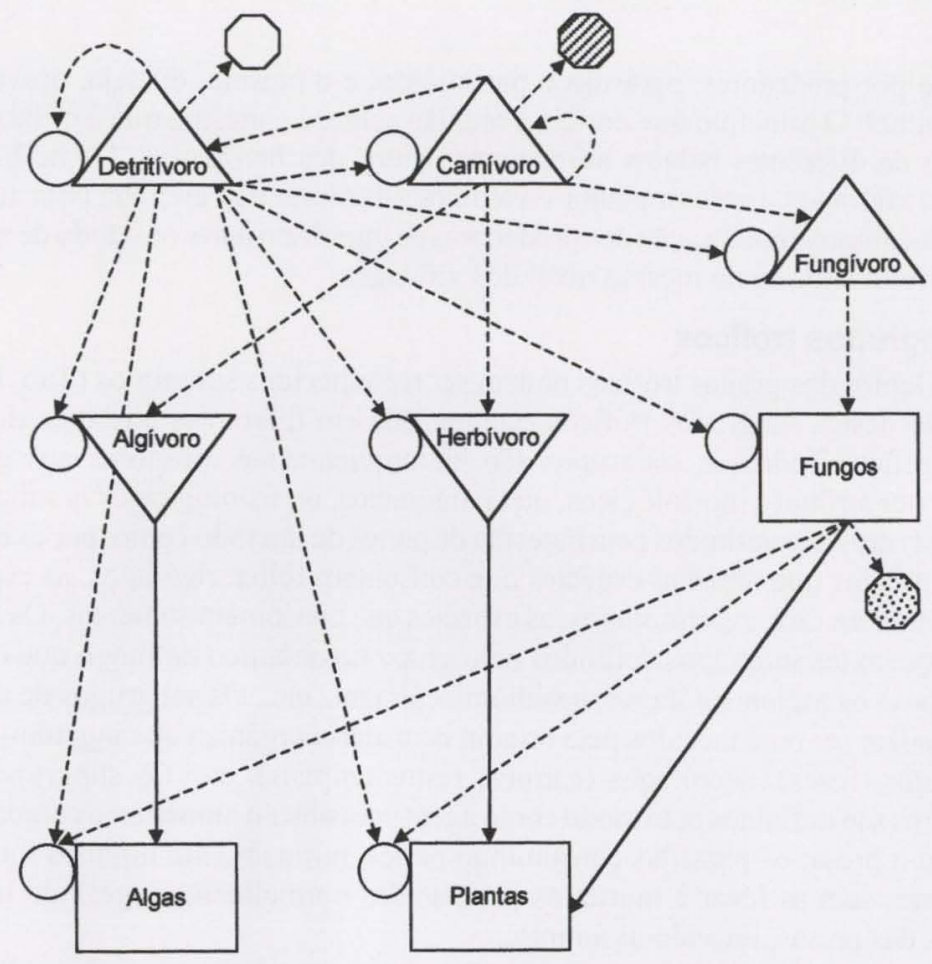

Fig. 1. Diagrama das relações tróficas em Coleoptera. Setas: em linha sólida indicam consumidor de primeiro nivel; em linha tracejada consumidor secundário ou de nível superior. Figuras geométricas: quadrado $=$ vegetais; triângulo $=$ coleópteros; circulo $=$ matéria $\mathrm{em}$ decomposição; hexágono azurado = presas animais de outros grupos taxonômicos, principalmente outros pequenos artrópodos e invertebrados, como moluscos, oligoquetos, nematódios; hexágono pontuado $=$ matéria de origem animal.

alimentares. Os quadrados estão relacionados aos vegetais; os triângulos aos coleópteros; os círculos ao material em decomposição originário da fonte a que está acolado, resultante de vegetais e coleópteros. Os hexágonos indicam outras fontes alimentares, diferentes das que provêm de vegetais e de coleópteros; o hexágono vazado (uma fonte dos detritívoros) representa a matéria em decomposição de origem animal; o hexágono azurado (uma fonte dos carnívoros) representa presas animais de outros grupos taxonômicos, principalmente pequenos invertebrados, como outros artrópodos, moluscos, anelídeos, etc.; o hexágono pontuado (uma fonte dos fungos) representa matéria de origem animal.

Observando o diagrama, uma seqüência de ingestão possível é - carnívoro $\rightarrow$ detritívoro $\rightarrow$ carnívoro morto $\rightarrow$ herbívoro $\rightarrow$ planta. O número de conexões será aumentado se admitida a possibilidade de um carnívoro comer outro carnívoro e do ingresso de outra fonte de recursos animais. As possibilidades do aumento de conexões é uma decorrência da disponibilidade de energia que passa de um nível trófico a outro, nos grupos dos detritívoros e dos carnívoros. 
Nesta rede é possível reconhecer a importância dos Coleoptera nos estudos de comunidades, principalmente das terrestres, onde estes insetos utilizam-se de praticamente todas as fontes de recursos alimentares disponíveis nos mais variados ambientes, desde as faixas litorâneas, passando pelos ambientes límnicos, zonas de campo e florestadas, atingindo as áreas frias, como as da região subantarctica.

\section{CONSIDERAÇÕES FINAIS}

Apesar das diferentes denominações que receberam os agrupamentos de espécies de coleópteros formados com base no hábito alimentar (grupo ecológico, categoria trófica, grupo trófico, guilda, guilda trófica, etc.), os objetivos de diversas pesquisas realizadas são fundamentalmente os mesmos. Ou seja, usar a dominância relativa de agrupamentos tróficos para servir como elemento indicador de condições ambientais, principalmente em ambientes florestados.

O conceito de guilda de Root (1967), "strictu sensu", foi pouco seguido, e hoje o termo vem sendo utilizado de uma forma generalizada para denominar "todo e qualquer grupo de espécies que são semelhantes de alguma maneira, que é ou pode ser, ecologicamente relevante (WILSON 1999). Resta ao pesquisador estabelecer uma conceituação precisa de guilda, através da descrição dos atributos que devem nortear a reunião das espécies. Os atributos podendo ser decorrentes do próprio recurso, das formas de sua obtenção, de relações temporal ou espacial no ambiente e outros.

Os hábitos alimentares dos Coleoptera são classificados em cinco grupos tróficos, reconhecendo-se a existência de consumidores primários (herbívoros e algívoros), consumidores secundários e superiores (fungívoros, detritívoros e carnívoros). O termo grupo trófico é aplicado dentro de uma classificação que apropria adequadamente um atributo alimentar a um táxon (espécie, gênero, tribo, ou categoria superior) e indica a reunião, em uma mesma classe, de todas as espécies que se utilizam de uma mesma fonte de recurso alimentar, independente do nível trófico. Os subgrupos tróficos, hierarquicamente inferiores aos grupos, estão formados por espécies que se assemelham no uso dos alimentos que têm os mesmos atributos morfológicos, ou que pertencem a um mesmo grupo taxonômico, ou ainda que se assemelham pelo modo de obtê-lo. Como decorrência de toda e qualquer característica biológica, existem fenômenos comportamentais que se apresentam como intermediários ou de transição entre os conceitos estritos de cada agrupamento. Nestas condições, a identificação trófica mais acertada para o táxon será uma decorrência do objetivo a ser alcançado pelo pesquisador, porém a aplicação da classificação ao nível de grupo trófico deve ser intensamente procurada para que os resultados possam ser mais substancial e consistentemente discutidos.

\section{REFERÊNCIAS BIBLIOGRÁFICAS}

Beley, J.R.; T.M. Ditswort; S.M. ButT \& C.D. JoHnson. 1982. Arthropods, plants and transmission lines in Arizona: community dynamics during secondary succession in a pinyon-juniper Chaparral habitat. The Southwestern Naturalist 27 (3): 325-333.

BRown, V.K. 1985. Insect herbivores and plant succession. Oikos 44 (1): 17-22.

BRown, V.K. \& P.S. HYMAN. 1986. Successional communities of plants and phytophagous Coleoptera. Jour. Ecol. 74 (4): 963-975. 
BRown, V.K. \& T.R.E. SOUTHWOOD. 1983. Trophic diversity, niche breadth and generation times of exopterigote insects in a secondary succession. Oecologia 56: 220-225.

BURNS, T.P. 1989. Lindeman's contradiction and the trophic structure of ecosystems. Ecology 70 (5): $1355-1362$.

ButT, S.M.; J.R. BEley; T.M. Ditsworth; C.D. Johnson \& R.P. BALDA. 1980. Arthropods, plants and transmission lines in Arizona: community dynamics during secondary succession in a desert grassland. Jour. Environ. Management 11: 267-284.

CoHEN, J.E. 1978. Food webs and niche space. Princeton, Princeton University Press.

CARLton, C.E. \& H.W. RoBinson. 1998. Diversity of litter-dwelling beetles in the Ouachita Highlands of Arkansas, USA (Insecta: Coleoptera). Biodiversity and Conservation 7: 1589-1605.

Costa, C.; S.A. VAnin; S.A. CASARI-ChEN. 1988. Larvas de Coleoptera do Brasil. São Paulo, Ed. Museu de Zoologia da Universidade de São Paulo.

Coulson, R.N.; R.O. Flamm; P.E. PUlley; T.L. PAyne; E.J. Rykiel \& T.L. WAgner. 1986. Response of the southern pine bark beetle guild (Coleoptera, Scolytidae) to host disturbance. Environ. Entomol. 15 (4): 850-858.

Crowson, R.A. 1981. The biology of the Coleoptera. London, Academic Press.

Cummins, K.W. 1974. Structure and function of stream ecosystems. Bioscience 24 (11): 631-641.

Deoca, E.M. \& G. HALFFTER. 1995. Daily and seasonal activities of a guild of the coprophagous, burrowing beetle (Coleoptera, Scarabaeidae, Scarabaeinae) in tropical grassland. Trop. Zool. 8 (1): 159-180.

Didham, R.K.; J.H. LAwton; P.M. Hammond \& P. EgGLETon. 1998. Trophic structure stability and extinction dynamics of beetles (Coleoptera) in tropical forest fragments. Philos. Trans. Royal Soc. London 353: 437-451.

Ditsworth, T.M.; S.M. ButT; J.R. Beley; C.D. Johnson \& R.P. BALDA. 1982. Arthropods, plants, and transmission lines in Arizona: community dynamics during secondary succession in a pinyon-juniper woodland. The Southwestern Naturalist 27 (2): 167-181.

Evans, F.C. \& W.W. Murdoch. 1968. Taxonomic composition, trophic structure and seasonal occurrence in a grassland insect community. Jour. Animal Ecol. 37: 259-273.

FinN, J.A., T. GitTINGS \& P.S. GILLER. 1999. Spatial and temporal variation in species composition of dung beetle assemblages in southern Ireland. Ecol. Entomol. 24 (1): 24-36.

FLAMM, R.O.; P.E. PULLEY \& R.N. COULSON. 1993. Colonization of disturbed trees by the southern pine bark beetle guild (Coleoptera, Scolytidae). Environ. Entomol. 22 (1): 62-70.

Flechtmann, C.A.H.; H.T.Z. Couto; C.L. Gaspareto \& E. Berti-Filho. 1995. Manual de pragas em florestas. Scolytidae em reflorestamento com pinheiros tropicais (4). Piracicaba, IPEF.

GASTON, K.J.; P.H. WARREN \& P.M. HAMmOND. 1992. Predator: non-predator ratios in beetle assemblages. Oecologia 90: 417-421.

HAWKINS, B.A. 1988. Species-diversity in the third and fourth trophic levels: patterns and mechanisms. Jour. Animal Ecol. 57 (1): 137-162.

Hawkins, C.P. \& J.A. MacMahon. 1989. Guilds: the multiple meanings of a concept. Ann. Rev. Entomol. 34: 423-451.

HeATWOLE, H. \& R. LEvins. 1972. Trophic structure stability and faunal change during recolonization. Ecology 53: 531-534.

Hengeveld, R. 1980. Polyphagy, oligophagy and food specialization in ground beetles (Coleoptera, Carabidae). Netherlands Jour. Zool. 30 (4): 564-584.

HERING, D. 1998. Riparian beetles (Coleoptera) along a small stream in the Oregon Coast Range and their interactions with the aquatic environment. Coleop. Bull. 52 (2): 161-170.

HodeK, I. 1996. Food relationships. 6, p.143-234. In: I. Hodek \& A. HonEK (Eds). Ecology of Coccinellidae. London, Kluwer Academic Publishers.

Holloway, B.A. 1982. Anthribidae (Insecta: Coleoptera). Fauna of New Zealand $\mathbf{n}^{\circ} 3$. Wellington, Science Information Division, DSIR.

HutCHESON, J. 1990. Characterization of terrestrial insect communities using quantified, 
Malaise-trapped Coleoptera. Ecol. Entomol. 15: 143-151.

HUTCHESON, J. \& D. JONES. 1999. Spatial variability of insect communities in a homogenous system: measuring biodiversity using Malaise trapped beetles in a Pinus radiata plantation in New Zealand. Forest Ecol. Management 118: 93-105.

JoHnSON, C.D. \& D.H. SiEMENS. 1995. Bruchid guilds, host preferences, and new host records from Latin America and Texas for the genus Stator Bridwell (Coleoptera, Bruchidae). Coleop. Bull. 49 (2): 133-142.

- 1997. Distribution, oviposition guilds, behavior and new host records from Latin America for Algarobius Bridwell, Scutobruchus Kingsolver and Pseudopachymerina spinipes (Erichson) (Coleoptera: Bruchidae). Coleop. Bull. 51 (1): 37-42.

JoHnSON, C.D.; J.R. BELEY; T.M. Ditsworth \& S.M. ButT. 1983. Secondary succession of arthropods and plants in the Arizona Sonoran Desert in response to transmission line construction. Jour. Environ. Management 16: 125-137.

Kalla, L.; P. Martikainen; P. Punttila \& E. Yakovlev. 1994. Saproxylic beetles (Coleoptera) on dead birch trunks decayed by different polypore species. Ann. Zool. Fennici 31: 97-107.

KISTLER, R.A. 1995. Influence of temperature on populations within a guild of mesquite bruchids (Coleoptera, Bruchidae). Environ. Entomol. 24 (3): 663-672.

LAwrence J.F. \& E.B.Britton. 1991. Coleoptera. In: CSIRO (Ed.). The Insects of Australia. New York, Cornell University Press, Vol. 2.

Lima, A.M. da C. 1952-56. Insetos do Brasil, Coleópteros. Rio de Janeiro, Escola Nacional de Agronomia, Vol. 7-10.

Lovelady, C.N.; P.E. Pulley; R.N. Coulson \& R.O. Flamm. 1991. Relation of lightning to herbivory by the southern pine bark beetle guild (Coleoptera, Scolytidae). Environ. Entomol. 20 (5): 1279-1284.

MARINONI, R.C. \& R.R.C. DUtRA. 1997. Famílias de Coleoptera capturadas com armadilha malaise em oito localidades do Estado do Paraná, Brasil. Diversidades alfa e beta. Revta bras. Zool. 14 (3): 751-770.

Marinoni, R.C.; N.G. Ganho; M. MonnÉ \& J.R. Mermudes. (no prelo). Hábitos alimentares em Coleoptera. Ribeirão Preto, Ed. Holos.

MiLLS, N.J. 1994. Parasitoid guilds: defining the structure of the parasitoid communities of endopterygote insect host. Environ. Entomol. 23 (5): 1066-1083.

MoEED, A. \& M.J. ME.ADS. 1985. Seasonality of pitfall trapped invertebrates in three types of native forest, Orongorongo Valley, New Zealand. New Zealand Jour. Zool. 12: 17-53.

Moran, V.C. \& T.R.E. SoutHWOOD. 1982. The guild composition of arthropod communities in trees. Jour. Animal Ecol. 51: 289-306.

Morris, M.G. 1980. Insects and the environment in the United Kingdom. Atti XII Congresso Nazionale Italiano di Entomologia, Roma, p. 203-235.

MUONA, J. \& I. RUTANEN. 1994. The short-term impact of fire on the beetle fauna in boreal coniferous forest. Ann. Zool. Fennici 31: 109-121.

Murrin, F. 1996. Fungi and insects, p. 365-388. In: D.H. Haward \& J.D. Miller (Ed.). The Mycota. Human and Animal Relationships. Berlin, Springer, Vol. 6.

PARMENTER, R.R. \& J.A. MACMAHON. 1987. Early successional patterns of arthropod recolonization on reclaimed strip mines in southwestern Wyoming: The ground-dwelling beetles fauna (Coleoptera). Environ. Entomol. 16 (1): 168-175.

Pellmyr, O. 1985. Flower constancy in individuals of an anthophilous beetle, Byturus ochraceus (Coleoptera: Byturidae). The Coleop. Bull. 39 (4): 341-345.

P ENNY , N.D. \& J.R. A RIAS . 1982. Insects of an amazon forest. New York, Columbia University Press. RiCKLEFS, R.E. 1990. Ecology. New York, W.H. Freeman and Company, $3^{\text {th }}$ ed.

Rоoт, R.B. 1967. The niche exploitation pattern of the blue-gray gnatcatcher. Ecol. Monogr. 37: $317-350$.

Sirtonen, J. 1994. Decaying wood and saproxylic Coleoptera in two old spruce forests: a comparison 
based on two sampling methods. Ann. Zool. Fennici 31: 89-95.

SIMANDL, J. 1993. The spatial pattern, diversity niche partitioning in xylophagous beetles (Coleoptera) associated with Frangula alnus Mill. Acta Oecol. Internat. Jour. Ecol. 14 (2): 161-171.

SimberLofF, D. \& T.DAYAN. 1991. The guild concept and the structure of ecological communities. Ann. Rev. Ecol. Syst. 22: 115-143.

SOUTHWOOD, T.R.E.; V.K. BROWN \& P.M. READER. 1979. The relationship of plant and insect diversities in succession. Biol. Jour. Linnean Soc. 12: 327-348.

Southwood, T.R.E.; V.C. MORAN \& C.E.J. KENNEDY. 1982. The richness, abundance and biomass of the arthropod communities on trees. Jour. Animal Ecol. 51: 635-649.

STORK, N.E. 1987. Guild structure of arthropods from Bornean rain forest trees. Ecol. Entomol. 12: 69-80.

Stribling, J.B. \& R.L. Seymour. 1988. Evidence of mycophagy in Ptilodactylidae (Coleoptera: Dryopoidea). Coleop. Bull. 42 (2): 152-154.

TANAKA, L.K. \& S.K. TANAKA. 1982. Rainfall and seasonal changes in arthropod abundance on a tropical oceanic island. Biotropica 14 (2): 114-123.

TorRE-BuEnO, J.R. 1978. A glossary of entomology. New York, Ed. G.S. Tulloch, New York Entomological Society, 335p.

WhITE, I.M. 1977. Larvae of some british species of Gyrophaena Mannerheim (Coleoptera-Saphylinidae) with notes on taxonomy and biology of the genus. Zool. Jour. Linnean Soc. 60 (4): 297-317.

W ILSON, J.B. 1999. Guilds, functional types and ecological groups. Oikos 86 (3): 507-522.

YoDzYs, P. 1982. The compartmentation of real and assembled ecosystems. Amer. Naturalist 120 551-570.

YodzYS, P. 1993. Environment and trophodiversity, p. 26-38. In: R.E. RickLefs \& D. SCHLUTER (Ed.).

Species diversity in ecological communities. Chicago, The University of Chigago Press.

Recebido em 20.XII.1999; aceito em 09.I.2001 